\title{
Application of Once-Monthly Self-Reported ACT Questionnaire in Management of Adherence to Inhalers in Outpatients with Asthma
}

This article was published in the following Dove Press journal: Patient Preference and Adherence

Jing Zhang ${ }^{1,2, *}$

Chengchen $\mathrm{Yin}^{1,3,4, *}$

Hongfang $\mathrm{Li}^{1,3,4}$

Weipeng Wei ${ }^{1,3,4}$

Yuansha Gong ${ }^{5}$

Fushan Tang 1,3,4

'Department of Clinical Pharmacy, School of Pharmacy, Zunyi Medical University, Zunyi 563006, People's Republic of China; ${ }^{2}$ Department of Respiratory Medicine, Central Hospital in Jinchang City (Worker's Hospital of Jinchuan Group), Jinchang 737102, People's Republic of China; ${ }^{3}$ The Key Laboratory of Clinical Pharmacy in Zunyi City, Zunyi Medical University, Zunyi 563006, People's Republic of China; ${ }^{4}$ Key Laboratory of Basic Pharmacology of Ministry of Education and Joint International Research Laboratory of Ethnomedicine of Ministry of Education, Zunyi Medical University, Zunyi 563006, People's Republic of China; ${ }^{5}$ School of Nursing, Zunyi Medical University, Zunyi 563006, People's Republic of China

*These authors contributed equally to this work
Purpose: Poor medication adherence can negatively affect health outcomes of patients with asthma from medication and significantly increase the healthcare costs. Management of adherence to inhalers remains a challenging topic in the long-term management of patients with asthma. We aim to evaluate the role of asthma control test (ACT) in the management of adherence to inhalers in outpatients with asthma.

Patients and Methods: Six hundred twenty-seven outpatients with asthma admitted to the clinic of respiratory medicine in a tertiary hospital in northwestern China during 2016 to 2019 were randomly divided into observation group $(n=315)$ and control $(n=312)$ and received standard inhalant therapy for 6 months and lung function test before and after treatment. The patients in the observation group took ACT questionnaires at the end of each month, while the patients in control only took an ACT at the end of the last month. The 'Test of Adherence to Inhalers' (TAI) questionnaire was used to evaluate the patients' adherence to inhalant therapy.

Results: All patients completed the study. The ACT scores in the observation group showed a gradual increase month by month. The TAI results indicated that adherence to inhalers of patients in the observation group was significantly better than that in control and the patients' non-adherence pattern in the observation group, with significantly lower erratic nonadherence, was also different from that in control. After 6 months of treatment, the lung function indexes and their relative improvement and the ACT scores in the observation group were significantly better or higher than those in control.

Conclusion: The once-monthly self-reported ACT can effectively improve the adherence to inhalers of outpatients with asthma mainly by addressing erratic non-adherence and improve the treatment effects, and thus deserves widespread use in the treatment adherence management in patients with asthma.

Keywords: asthma control test, ACT, medication adherence, Test of Adherence to Inhalers, TAI, self-management, China

\section{Introduction}

Asthma is an inflammatory disorder of the airways associated with reversible airway obstruction causing dyspnea, wheeze, and coughing. In addition to daily symptoms, asthma patients may also experience serious life-threatening attacks. To achieve good symptom control and minimize future risk of asthma-related mortality, exacerbations, persistent airflow limitation and side-effects of treatment, guidelines recommend that most patients with asthma should be prescribed regular inhaled corticosteroids (ICS),
Correspondence: Fushan Tang Department of Clinical Pharmacy School of Pharmacy, Zunyi Medical University, Zunyi 563006, People's Republic of China Tel +8685I 28642337

Fax +8685128642334

Email fushantang@qq.com 
as well as a reliever medicine for as-needed use. ${ }^{1}$ Though inhaled medicines play a key role in the long-term treatment of asthma and the improvement of medication adherence to inhaled medicines might contribute to a better prognosis in patients with asthma, ${ }^{2,3}$ poor adherence is still a major problem among patients with asthma, negatively affecting health outcomes and significantly increasing treatment costs. On average, $50 \%$ of patients with asthma fail to adhere to the recommendations of their healthcare provider. ${ }^{4-6}$ In addition, previous reports have demonstrated that adherence to inhaled medicines is worse than that to oral, injected, and transdermal medicines. ${ }^{7-10}$ Therefore, management of medication adherence to inhalers remains a challenging topic in the long-term management of asthma patients.

Asthma control test (ACT) is a simple retrospective assessment of asthma control. It can easily and quickly screen out patients with poor asthma control. The 2019 edition of GINA clearly proposes ACT score as useful tool of great benefit to patients' self-monitoring and assessment of asthma control. "Test of Adherence to Inhalers" (TAI) is a reliable and homogeneous questionnaire to identify easily non-adherence and to classify from a clinical perspective the barriers related to the use of inhalers in patients with asthma and COPD. ${ }^{11,12}$

Guided self-management has been considered as the gold standard to achieve optimal asthma control, which highlights patients' day-to-day self-monitoring and selfmanagement of the disease following physicians' guidance. ${ }^{13,14}$ In this study, with ACT as main intervention for adherence to inhalers and TAI as questionnaire instrument to measure adherence to inhalers of patients, we investigated role of once-monthly self-reported ACT questionnaire carried out by patients themselves under guidance of physicians and pharmacists in management of adherence to inhalers in outpatients with asthma.

\section{Patients and Methods}

\section{Participants}

Six hundred twenty-seven patients with asthma were collected from the clinic of respiratory medicine in a citylevel central hospital in northwestern China during February 2016 to July 2019, including 295 males and 332 females, aged 19-68 (42.7 \pm 11.8$)$ years, with a course of 8 months $\sim 35$ years. All patients were randomly divided into observation group $(n=315)$ and control group $(n=312)$. There were no significant differences in gender, age, disease duration and condition between the two groups $(\mathrm{P}>0.05)$.

\section{Inclusion Standard}

All patients were diagnosed according to the diagnostic criteria for bronchial asthma prevention and treatment guidelines developed by the Asthma workgroup of the Chinese Medical Association Respiratory Diseases Branch. ${ }^{15,16}$ All patients were older than 18 years of age, and were able to understand and complete the ACT and TAI questionnaire. The participants included both newly diagnosed patients and patients with already existing asthma. And the different kinds of patients were equally randomized into the observation and control group. Patients with asthma exacerbation were included when they started inhaled treatment after their severe acute symptoms were controlled by intravenous or oral glucocorticoid and/or bronchodilators. Severe patients account for about $10 \%$ of the total number of participant asthma patients and the number of severe patients in the two groups was roughly equal. Exclusion: difficult to understand the content of the test questionnaire; respiratory infection within 1 month; combined with other lung diseases or chronic heart, liver and kidney diseases; pregnant women.

\section{Control Group}

The patients were treated with standardized medication of combination of inhaled corticosteroids (ICS) and longacting $\beta_{2}$ receptor agonists (LABA) for asthma control and health education (involving inhaler technique training helpful for patients to use the inhalers correctly, Figure 1).

\section{Observation Group}

On the basis of the control group, the patients in this group took the self-reported ACT questionnaire at the end of each month after starting treatment and were asked to bring the ACT results to physicians or pharmacists at the next visit or to send the results to physicians or pharmacists through Wechat or email immediately after the questionnaire was finished (Figure 1). The patients' asthma control was tested in five levels from influence of asthma to daily activities, the frequency of asthma attacks, the frequency of nighttime asthma, the frequency of use of reliever (rescue) medicine and the general self-assessment in the past 4 weeks with scores of the five problems were added to calculate the total ACT score. The ACT score interpretation criteria: 25 for complete asthma control; 


\begin{tabular}{|c|c|c|}
\hline & $\begin{array}{l}\text { Patients included } \\
\qquad n=627\end{array}$ & \\
\hline $\begin{array}{l}\text { Control } \\
n=312\end{array}$ & \multicolumn{2}{|r|}{$\begin{array}{l}\text { Observation group } \\
\qquad \mathrm{n}=315\end{array}$} \\
\hline $\begin{array}{l}\text { Day 0: } \\
\text {-- Pulmonary function measurement } \\
\text {-- Inhaler technique training }\end{array}$ & $\begin{array}{l}\text { Day } 0 \\
-- \text { Pul } \\
-- \text { Inh } \\
--\mathrm{ACT}\end{array}$ & $\begin{array}{l}\text { lary function measurement } \\
\text { technique training } \\
\text { ining }\end{array}$ \\
\hline $\begin{array}{l}\text { Month 1-6: } \\
\text {-- Standardized inhaler therapy }\end{array}$ & $\begin{array}{l}\text { Mont } \\
-- \text { Star } \\
--\mathrm{ACT}\end{array}$ & $\begin{array}{l}6: \\
\text { rdized inhaler therapy } \\
\text { the end of every month }\end{array}$ \\
\hline $\begin{array}{l}\text { The end of month 6: } \\
\text {-- TAI (Test of adherence to inhalers) } \\
\text {-- Pulmonary function measurement } \\
\text {-- ACT (Asthma control test) }\end{array}$ & $\begin{array}{l}\text { The e } \\
\text {-- TAl } \\
\text {-- Pull }\end{array}$ & $\begin{array}{l}\text { of month 6: } \\
\text { st of adherence to inhalers) } \\
\text { nary function measurement }\end{array}$ \\
\hline
\end{tabular}

Figure I Flowchart of the study design and procedures.

20-24 for partial to good asthma control; 19 and less for poor asthma control. ${ }^{1}$

The patients in the observation group were guided by physicians and pharmacists on the significance of ACT and how to complete the ACT questionnaire on the first day of the study. The patients in the control group were given the same counselling as the patients in the observation group by physicians and pharmacists before taking the ACT questionnaire. The guidance of physicians and pharmacists in performing ACT usually means that the respiratory physicians explained to the patients the significance of ACT and the knowledge related to disease and symptom control in ACT and that the pharmacists explained to patients the relevant knowledge of inhalation therapy in ACT. These instructions are for the general situation of all patients in both groups and were therefore relatively chief and concise. All the physicians and pharmacists involved in the study understood the importance of homogeneity of guidance to patients for the results of the adherence study and were able to counsel each patient participating in the study with basically the same procedure and words.

\section{Observation Indicators Medication Adherence}

We adopted "Test of the Adherence to Inhalers" questionnaire (TAI, including 12 items with two main domains, items \#1 to \#10 for the patient domain and items \#11 and
\#12 for the health professional domain) to assess patients' adherence with inhalant therapy: the 10-items TAI scores were adopted to identify non-adherent patients and to establish the non-adherence level with cut-offs of 50 for adherent patients with complete adherence with inhalant therapy, 46 to 49 for intermediate adherent patients with relatively good adherence, and $\leq 45$ for poor-adherent patients with poor adherence; whereas the 12-items TAI scores were used to orient the non-adherence as erratic, deliberate and unwitting patterns. A non-adherent behavioral pattern was defined as erratic and deliberate when total scores $\leq 24$ for items \#1 to \#5 and items \#6 to \#10, respectively. The unwitting pattern was defined when total scores $\leq 3$ for items \#11 and \#12 of the questionnaire. ${ }^{11}$

\section{Lung Function Measurement}

We used the quark4 lung function meter manufactured by COSMED Company in Italy to measure and compare the lung function [FEV1 (forced expiratory volume in one second), PEF (peak expiratory flow) and FVC (forced vital capacity), all indexes were recorded as percent predicted ones] of the two groups of patients before and after 6 months of treatment.

\section{Statistical Analysis}

SPSS 17.0 statistical software was used to analyze the data. Measurement data were expressed as mean \pm standard 
deviation and the differences were analyzed with $t$-test; the differences between count data were analyzed with chi square test. The difference was considered statistically significant as $P<0.05$.

\section{Results}

\section{Comparison of Medication Adherence}

There were $213(67.62 \%)$ patients with good adherence (adherents and intermediate adherents) and 102 (32.38\%) patients with poor adherence in the observation group; 158 (50.64\%) patients with good adherence and 154 (49.36\%) patients with poor adherence in control, respectively (Table 1). Patients in the observation group had higher scores on most questions of items \#1 to \#10 of the TAI questionnaire (Figure 2A) and better medication adherence in total (more adherents and intermediate-adherents and less poor-adherents) than in control (Table 1).

If only poor adherence was taken as non-adherence, the non-adherence rate to inhaler therapy in this study was $49.36 \%$ in control and $32.38 \%$ in the observation group and the difference between the two groups was statistically significant. If both intermediate adherence and poor adherence were included into non-adherence, though the difference between two groups was still statistically significant, the non-adherence rate appeared very high in both of groups $(86.67 \%$ in observation group vs $92.31 \%$ in control). As for non-adherent behavioral pattern, there were less unwitting non-adherents in observation group than in control; the erratic non-adherents in observation group were significantly less than that in control; but the deliberate non-adherence was similar between the two groups (Figure 2B, Table 1).

Table I Comparison of Patients' Adherence to Inhalers Between the Two Groups

\begin{tabular}{|l|l|l|}
\hline & Control (\%) & Observation (\%) \\
\hline Adherents & $24(7.69)$ & $42(13.33)^{*}$ \\
Intermediate adherents & $134(42.95)$ & $171(54.29)^{*}$ \\
Poor adherents & $154(49.36)$ & $102(32.38)^{*}$ \\
Erratic non-adherents & $230(73.72)$ & $124(39.37)^{* *}$ \\
Deliberate non-adherents & $157(50.32)$ & $172(54.60)$ \\
Unwitting non-adherents & $119(38.14)$ & $83(26.35)^{*}$ \\
\hline Total & 312 & 315 \\
\hline
\end{tabular}

Notes: Non-adherents include intermediate and poor adherents, and the nonadherence was subdivided as erratic, deliberate and unwitting patterns. *Compared with control, $P<0.05$; **Compared with control, $P<0.01$.

\section{Comparison of Lung Functions}

The lung functions of patients before treatment were statistically similar between two groups; the lung functions of patients in both groups were significantly improved by treatment; the improved extents of lung function indexes in the observation group were greater than those in control; and the lung function indexes of patients in observation group were significantly better than those in control (Table 2).

\section{ACT Scores}

ACT scores of patients in the observation group kept increasing month by month during the treatment study period of 6 months, indicating improving asthma control (Figure 3A); and the comparison of ACT scores at the end of the last month suggested patients in the observation group had better asthma control with more completely controlled and less poorly controlled patients than those in the control group (Figure 3B).

\section{Discussions}

Bronchial asthma is a common chronic airway inflammatory disease causing great harm to the quality of life of patients. Successful asthma management requires patients to adhere to recommendations on timely therapy, asthma control monitoring and avoidance of environmental triggers. ${ }^{17,18}$ Whether asthma patients adhere to therapy has a significant impact on improvement in their quality of life and disease outcomes. ${ }^{19-21}$ Inhalant therapy is the main treatment for asthma control, and adherence management of inhalant therapy is one of the key points of asthma management. ${ }^{22,23}$ However, the poor patients' adherence to inhalers and lack of easy disease assessment and timely guidance for treatment may limit the effects of inhalant therapy. Suboptimal or non-adherence to inhaled therapies for asthma was believed to be associated with poor symptom control, higher healthcare utilization and healthcare costs, and reductions in health-related quality of life. ${ }^{24}$ Currently, only limited researchers have conducted indepth and comprehensive research on medication adherence interventions for asthma patients. ${ }^{1}$ It is urgent to work closely with patients and take patient beliefs and preferences into account to establish a treatment model of shared decision-making, thus improving adherence and overall patient outcomes in the management of asthma. ${ }^{25}$

In 2004, Nathan et al developed a brief, easy to administer and patient-based tool for identifying patients with 


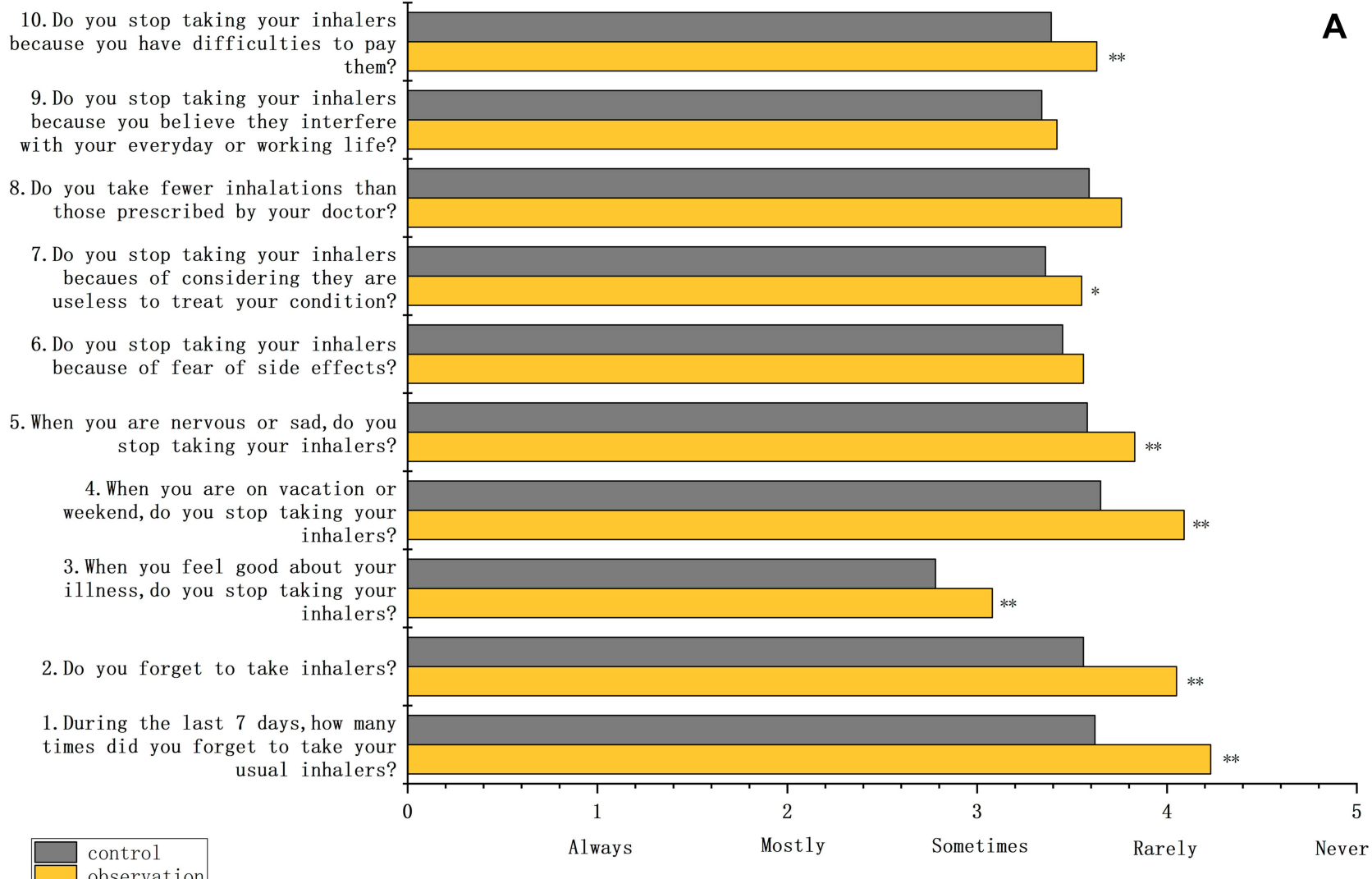

observation

12. The technique of using the evaluated inhaler device by the patient is(Without critical

mistakes, 2) 12. The technique of using the evaluated inhaler device by the patient is (With critical mistakes, 1)

11. Does the patient remember the prescribe dregimen(dose and frequency) ? (No, 1)

11. Does the patient remember the prescribe dregimen(dose and frequency)? (Yes, 2)

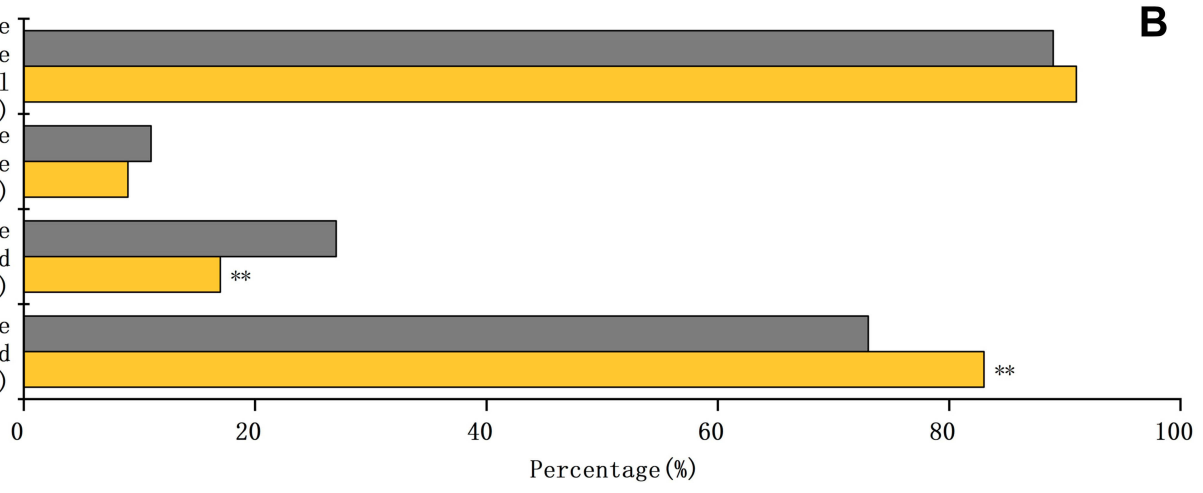

Figure 2 TAI results of patients: (A) average scores of items I-I0; (B) patients' choice on items II and I2. $*$ Compared with control, $P<0.05$; $* *$ compared with control, $P<0.0$ I.

poorly controlled asthma, the Asthma Control Test (ACT), which includes four symptom/reliever questions plus a patient self-assessed level of control and its aspects reflect the focus of current asthma management guidelines. ${ }^{26} \mathrm{ACT}$ is believed to be reliable, valid, and responsive to changes in asthma control over time and considered to be an effective method for assessing asthma control by guiding patients to use ACT to assess their condition and adjust treatment options. ${ }^{27}$ It may have the potential to be an effective management tool for improving patient adherence. As we all know, monthly exams can improve students' adherence to teachers' guidance and their motivation and performance. Inspired by the successful practice of formative evaluation in teaching and patient care fields, ${ }^{28-30}$ we adopted once-monthly ACT to identify its potential and actual influences on patients' adherence to and treatment effects of inhalant therapy. The self-reported ACT questionnaire was used as not only an evaluation tool of asthma control for all patients, also the specific intervention for self-management of medication adherence of asthma patients specifically in the observation group in this study. As far as the specific situation of this study is 
Table 2 Comparison of Lung Function of Patients Between Two Groups (Mean \pm SD)

\begin{tabular}{|l|l|l|l|}
\hline \multicolumn{2}{|c|}{} & Control (\%) & Observation (\%) \\
\hline FEVI\% pred & Before treatment & $56.12 \pm 13.02$ & $56.05 \pm 13.49^{\mathrm{a}}$ \\
& After treatment & $67.31 \pm 11.47^{\mathrm{b}}$ & $76.63 \pm 12.64^{\mathrm{b}, \mathrm{c}}$ \\
& Improvement & $19.94 \pm 3.47$ & $36.72 \pm 7.64^{\mathrm{c}}$ \\
\hline PEF \% pred & Before treatment & $63.15 \pm 7.34$ & $63.42 \pm 6.72^{\mathrm{a}}$ \\
& After treatment & $78.21 \pm 6.86^{\mathrm{b}}$ & $89.86 \pm 7.13^{\mathrm{b}, \mathrm{c}}$ \\
& Improvement & $23.85 \pm 2.64$ & $41.69 \pm 5.78^{\mathrm{c}}$ \\
\hline \multirow{2}{*}{ FVC \% pred } & Before treatment & $78.46 \pm 11.07$ & $78.28 \pm 11.85^{\mathrm{a}}$ \\
& After treatment & $84.94 \pm 11.45^{\mathrm{b}}$ & $92.63 \pm 11.26^{\mathrm{b}, c}$ \\
& Improvement & $8.26 \pm 1.84$ & $18.33 \pm 3.16^{\mathrm{c}}$ \\
\hline
\end{tabular}

Notes: ${ }^{\mathrm{a} C}$ Compared with control, $P>0.05$; ${ }^{\mathrm{b}}$ Compared with that before treatment, $P<0.05$; 'Compared with control, $P<0.05$.

concerned, the once-monthly self-reported ACT conducted by the patients in the observation group is to encourage the patients to self-manage the treatment process of asthma; while the last ACT in both groups was mainly used to evaluate and compare the asthma control level between the observation and control group.

The average rate of adherence in asthma is believed to be between $30-70 \%$ dependent on the accuracy of the measurement method. ${ }^{17}$ If we adopted the relatively strict definition of non-adherence suggested by the TAI founders, ${ }^{11}$ which included both intermediate adherence and poor adherence into non-adherence, the nonadherence rate to inhaler therapy in this study appeared very high $(86.67 \%$ in observation group; $92.31 \%$ in control). This suggests that strengthening the management of patients' adherence to inhaler therapy is still a key and tough issue for rational clinical drug use and need to be discussed and resolved urgently. If only poor adherence was taken as non-adherence, the non-adherence rate to inhaler therapy in this study was $49.36 \%$ in control and $32.38 \%$ in the observation group, similar with those were reported in earlier literatures. ${ }^{31-36}$

Regardless of the strict or loose definition of noncompliance, the differences between the adherence rates in the observation group and in control were both statistically significant. There were more complete and intermediate adherents and fewer poor adherents in observation group than those in control. This suggested that the once-monthly ACT administered to outpatients with asthma can effectively promote patients to follow the guidance from medical professionals and improve their adherence to inhalant therapy. The non-adherence can be subdivided as erratic, deliberate and unwitting behavior patterns, ${ }^{11}$ or intentional and unintentional nonadherence. The erratic and unwitting non-adherence can be included into unintentional non-adherence, and deliberate non-adherence and intentional non-adherence usually can be taken as the same thing. There were fewer erratic and unwitting non-adherents in the observation group than those in control, while the proportions of deliberate nonadherents in two groups were similar. This indicated that the once-monthly self-reported ACT may reduce unintentional non-adherence through patients without strong nonadherent belief or perceptions being reminded or alerted by themselves around they conducting the ACT questionnaire to follow and persist on treatment recommendations. Usually, erratic and unwitting non-adherent behaviors can be corrected by patient education, simplification of treatment regimens, or the use of a reminder system, unintentional non-adherence is thus easier to remedy; while intentional non-adherence is more complex and challenging to address because the patients related to these behaviors often have difficult to recognize the importance of evidence-based recommendations or have deep-rooted personal beliefs that conflict with health guidance. ${ }^{37}$

Though it can be reasonably believed that even modest improvements in adherence may result in clinical benefits, ${ }^{17}$ the impact of improved adherence to inhaled therapy on quality of life and asthma control remained uncertain and inconsistent to some extent. ${ }^{38}$ The clinical relevance of improvements by any interventions in adherence for asthma need to be confirmed. In this study, the patients with asthma in both the control and the observation group were treated with inhalant therapy and their lung functions before and after treatment were tested and recorded as percent predicted FEV1, PEF and FVC. The patients in the observation group were specially administered with once-monthly ACT as intervention being expected to improve patients' adherence to inhalers and thus asthma control effects, while the patients in control only took an ACT questionnaire at the end of the treatment study for the purpose to compare the asthma control effects between two groups. The results showed that the improvements in the indexes of lung functions of patients in the observation group were significantly greater than those in control, and the comparison of ACT scores at the end of the treatment study period suggested patients in the observation group had better asthma control with more completely controlled and fewer poorly controlled patients than in the control group. During the 6-month study period, there was no difference in communication and 

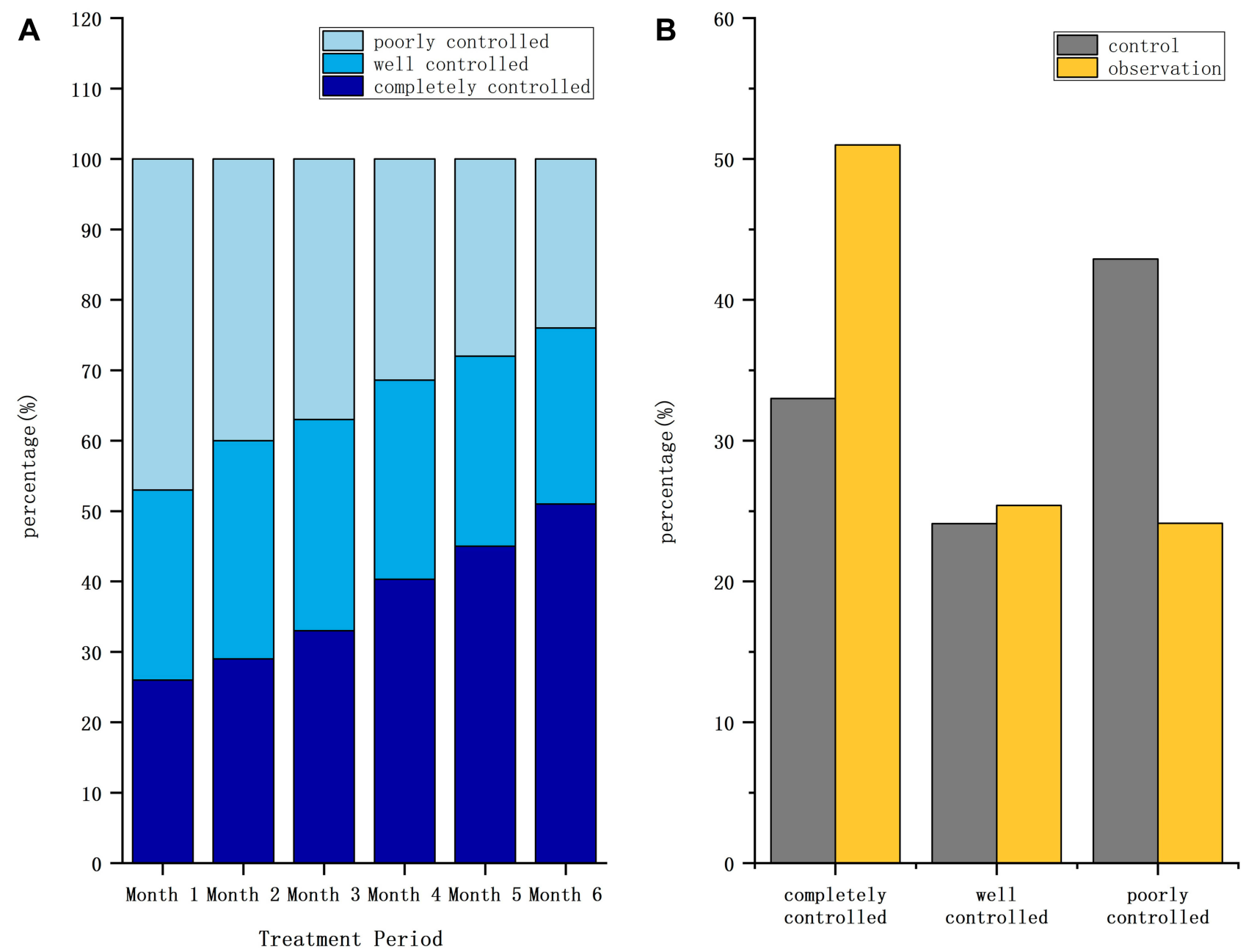

Figure 3 Asthma control evaluated by ACT scores: $(\mathbf{A})$ in the observation group; (B) comparison between control and the observation group after treatment.

medication guidance between the observation group and the control group. Therefore, the differences in adherence and pulmonary function between the two groups after the 6-month study should be mainly attributed to the monthly self-reported ACT questionnaire. The significant improvements in adherence to inhalers and lung functions in ACTadministered patients indicate that ACT can play an important substantial role in managing adherence to inhalers in patients with asthma. Since the erratic nonadherence accounted for the largest proportion of medication non-adherence (in the control group in this study, $73.72 \%$ of patients were erratic non-adherents), the significant improvements in adherence may be mainly related to great gain in erratic non-adherence by the intervention of the once-monthly self-reported ACT.

The ACT scores of patients in the observation group kept increasing month by month during the treatment study period of 6 months, and the ACT scores of patients in control group obtained from the questionnaire only once at the end of the sixth month of the treatment study period were similar with those at the end of the second month and significantly lower than those at the end of the sixth month in the observation group. This further demonstrated that the once-monthly ACT can substantially improve asthma control. As a questionnaire tool for assessment of asthma control, ACT cannot improve asthma control directly. The mechanism underlying this substantial effect can reasonably contribute to the role of ACT to improve patients' adherence to treatment by addressing erratic non-adherence through the patients being reminded or alerted by themselves to follow and persist on treatment recommendations and promote healthy patient-health professional partnership required by effective asthma management. The true patient-health professional partnership should ensure effective communication between both parties to arrive at mutually agreed 
goals in concordance. ${ }^{39}$ The monthly ACT may reach a consensus on goals of asthma management thus improving the patient's consciousness and persistence to collaborate with medical professionals in the implementation of drug treatment and other interventions, ultimately improving asthma control in patients. Therefore, the ACT can be an important link in the continuous cycle of assessment, treatment, and review of the patient's response, and can help medical professionals to make appropriate decisions about asthma treatment taking patient's preferences into account. $^{1}$

It was noted that the introduction of ACT in asthma treatment adherence management had little effect on improving deliberate or intentional non-adherence to inhalers and relatively limited effects on unwitting non-adherence regardless of its very significant effects on improving erratic nonadherence. This suggests that giving full play to the role of ACT in the adherence management of asthma patients must be combined with adequate patient-oriented health education including medication guidance. A reasonable patient-health professional partnership required by effective asthma management needs the patients to have certain ability to obtain, process and understand basic health information to make proper health decisions. ${ }^{1}$ It has been reported that education by a pharmacist combined with an auto refill program can improve and sustain appropriate inhaler use. ${ }^{40}$ Though the ACT is usually performed by patients themselves, the implementation process must emphasize the guiding role of medical professionals on patients with asthma.

Any intervention that targets patient non-adherence in asthma control must be consistent with local practices and the availability of health care resources. ${ }^{1}$ Compared with some other studied interventions to improve patients' adherence to inhalant therapy, such as shared decision-making for medication/dose choice, ${ }^{41,42}$ inhaler reminders, ${ }^{43-45}$ home visit by medical professionals, ${ }^{46}$ automated voice recognition programme, ${ }^{47}$ and telemedicine oversight, ${ }^{48}$ ACT does not require special equipment and human resources, making it a relatively simple, economical, reliable, and adaptable tool to be used in various clinical settings.

\section{Conclusions}

The once-monthly self-reported ACT questionnaire can effectively improve adherence to inhalers of patients with asthma mainly by addressing erratic non-adherence through the patients being reminded or alerted by themselves to follow and persist on treatment recommendations and thus improve the lung function and asthma control of patients. ACT is feasible, economical, efficient and reliable as intervention for non-adherence to inhalers and can be widely used in asthma management in outpatients in combination with necessary health education on patients.

\section{Considerations for Future Research}

More attention should be paid to patient's beliefs, perceptions, expectations, needs, self-efficacy and quality of life in the future study; the role in non-adherence intervention of family members or caregivers of asthma patients should be taken into account; different interventions may need be designed for new and returning patients; different interventions may be needed for asthma patients with different severity; health education on patients should be strengthened to improve their health literacy with ACT and/or other interventions; the impact of the regular patient-to-doctor or patient-to-pharmacist contact on adherence to inhalers of asthma patients should be investigated specifically.

\section{Ethical Approval}

The study was approved by the ethical committee of Central Hospital in Jinchang City, China (2014-027) and conducted in accordance with the Declaration of Helsinki. Most of the participants provided written informed consents, and a small part of participants who cannot read or write provided verbal informed consents, which was approved by the ethics committee.

\section{Acknowledgments}

This work was financially supported by the Key Discipline of Zunyi Medical University in Clinical Pharmacy. We thank all the patients, who generously participated in the research, and all the physicians, pharmacists and nurses who took part in the research. Jing Zhang and Chengchen Yin are co-first authors for this study.

\section{Disclosure}

The authors declare that they have no competing interests in this work.

\section{References}

1. Global Initiative for Asthma. Global strategy for asthma management and prevention [Internet]; 2019. Available from: www.ginasthma.org. Accessed Oct 17, 2019.

2. Park J, Jackson J, Skinner E, Ranghell K, Saiers J, Cherney B. Impact of an adherence intervention program on medication adherence barriers, asthma control, and productivity/daily activities in patients with asthma. J Asthma. 2010;47(10):1072-1077. doi:10.3109/02770903. 2010.485660 
3. Williams LK, Peterson EL, Wells K, et al. Quantifying the proportion of severe asthma exacerbations attributable to inhaled corticosteroid nonadherence. J Allergy Clin Immunol. 2011;128(6):1185-1191.e2. doi:10.1016/j.jaci.2011.09.011

4. Martin LR, Williams SL, Haskard KB, Dimatteo MR. The challenge of patient adherence. Ther Clin Risk Manag. 2005;1(3):189-199.

5. World Health Organization. Adherence to long-term therapies: evidence for action; 2003. Available from: http://www.who.int/chp/ knowledge/publications/adherence_report/en/. Accessed Nov 20, 2018

6. Bozek A, Jarzab J. Adherence to asthma therapy in elderly patients. J Asthma. 2010;47(2):162-165. doi:10.3109/02770900903497204

7. Jones C, Santanello NC, Boccuzzi SJ, Wogen J, Strub P, Nelsen LM. Adherence to prescribed treatment for asthma: evidence from pharmacy benefits data. J Asthma. 2003;40(1):93-101. doi:10.1081/jas120017212

8. Rand C, Bilderback A, Schiller K, et al. Adherence with montelukast or fluticasone in a long-term clinical trial: results from the mild asthma montelukast versus inhaled corticosteroid trial. J Allergy Clin Immunol. 2007;119(4):916-923. doi:10.1016/j.jaci.2006.12.664

9. Broder MS, Chang EY, Ory C, Kamath T, Sapra S. Adherence and persistence with omalizumab and fluticasone/salmeterol within a managed care population. Allergy Asthma Proc. 2009;30(2):148-157. doi:10.2500/aap.2009.30.3190

10. Tamura G, Ohta K. Adherence to treatment by patients with asthma or COPD: comparison between inhaled drugs and transdermal patch. Respir Med. 2007;101(9):1895-1902. doi:10.1016/j.rmed.2007.05.001

11. Plaza V, Fernández-Rodríguez $\mathrm{C}$, Melero $\mathrm{C}$, et al. Validation of the 'Test of the Adherence to Inhalers' (TAI) for asthma and COPD patients. J Aerosol Med Pulm Drug Deliv. 2016;29(2):142-152. doi:10.1089/jamp.2015.1212

12. Plaza V. Update on questionnaires for assessing adherence to inhaler devices in respiratory patients. Curr Opin Allergy Clin Immunol. 2018;18(1):44-50. doi:10.1097/ACI.0000000000000410

13. Lougheed MD, Leniere C, Ducharme FM, et al. Canadian Thoracic Society 2012 guideline update: diagnosis and management of asthma in preschoolers, children and adults: executive summary. Can Respir J. 2012;19(6):e81-e88. doi:10.1155/2012/214129

14. National Heart, Lung, and Blood Advisory Council Asthma Expert Working Group. Guidelines for the diagnosis and management of asthma; April 2014. Available from: https://www.nhlbi.nih.gov/files/ docs/resources/lung/NHLBAC-Asthma-WG-Report.pdf. Accessed Oct 17, 2018.

15. Chinese Medical Association Respiratory Branch Workgroup of Asthma. Guidelines for prevention and treatment of bronchial asthma (2016 Edition). Chin J Tuberc Respir Dis. 2016;39(9):675-697. doi:10.3760/ema.j.issn.1001-0939.2016.09.007

16. Chinese Medical Association Respiratory Branch Workgroup of Asthma, Chinese Medical Association General Medicine Branch. Chinese guideline for the prevention and management of bronchial asthma (primary health care version). Chin J Tuberc Respir Dis. 2013;36(5):331-336. doi:10.3760/cma.j.issn.1001-0939.2013.05.007.

17. Boulet LP, Vervloet D, Magar Y, Foster JM. Adherence: the goal to control asthma. Clin Chest Med. 2012;33(3):405-417. doi:10.1016/j. ccm.2012.06.002

18. Papaioannou AI, Kostikas K, Zervas E, Kolilekas L, Papiris S, Gaga M. Control of asthma in real life: still a valuable goal? Eur Respir Rev. 2015;24(136):361-369. doi:10.1183/16000617.00001615

19. Rabe KF, Adachi M, Lai CK, et al. Worldwide severity and control of asthma in children and adults: the global asthma insights and reality surveys. J Allergy Clin Immunol. 2004;114(1):40-47. doi:10.1016/j. jaci.2004.04.042

20. Williams LK, Pladevall M, Xi H, et al. Relationship between adherence to inhaled corticosteroids and poor outcomes among adults with asthma. J Allergy Clin Immunol. 2004;114(6):1288-1293. doi:10.10 16/j.jaci.2004.09.028
21. Kim C, Feldman HI, Joffe M, Tenhave T, Boston R, Apter AJ. Influences of earlier adherence and symptoms on current symptoms: a marginal structural models analysis. J Allergy Clin Immunol. 2005;115(4):810-814. doi:10.1016/j.jaci.2004.11.032

22. McCracken JL, Veeranki SP, Ameredes BT, Calhoun WJ. Diagnosis and management of asthma in adults: a review. JAMA. 2017;318 (3):279-290. doi:10.1001/jama.2017.8372

23. O'Byrne PM, Mejza F. Advances in the treatment of mild asthma: recent evidence. Pol Arch Intern Med. 2018;128(9):545-549. doi:10.20452/pamw.4341

24. Mäkelä MJ, Backer V, Hedegaard M, Larsson K. Adherence to inhaled therapies, health outcomes and costs in patients with asthma and COPD. Respir Med. 2013;107(10):1481-1490. doi:10.1016/j. rmed.2013.04.005

25. George M, Bender B. New insights to improve treatment adherence in asthma and COPD. Patient Prefer Adherence. 2019;13:1325-1334. doi:10.2147/PPA.S209532

26. Nathan RA, Sorkness CA, Kosinski M, et al. Development of the asthma control test: a survey for assessing asthma control. J Allergy Clin Immunol. 2004;1:59-65. doi:10.1016/j.jaci.2003.09.008

27. Schatz M, Sorkness CA, Li JT, et al. Asthma control test: reliability, validity, and responsiveness in patients not previously followed by asthma specialists. J Allergy Clin Immunol. 2006;117(3):549-556. doi:10.1016/j.jaci.2006.01.011

28. Tang F. Enlightenment of training mode of Pharm. D. Project in University of Nebraska Medical Center to Chinese pharmacy education. Chin Pharm. 2018;29(20):2737-2741. doi:10.6039/j. issn.1001-0408.2018.20.01

29. Luvira V, Bumrerraj S, Srisaenpang S. Formative evaluation and learning achievement in epidemiology for preclinical medical students. Indian J Community Med.2018;43(4):298-301.doi:10.4103/ijcm.IJCM_191_18

30. Elwy AR, Wasan AD, Gillman AG, et al. Using formative evaluation methods to improve clinical implementation efforts: description and an example. Psychiatry Res. 2020;283:112532. doi:10.1016/j. psychres.2019.112532

31. Ershad Sarabi R, Sadoughi F, Jamshidi Orak R, Bahaadinbeigy K. The effectiveness of mobile phone text messaging in improving medication adherence for patients with chronic diseases: a systematic review. Iran Red Crescent Med J. 2016;18(5):e25183. doi:10.5812/ircmj.25183

32. Bender B, Boulet LP, Chaustre I, et al. Asthma. In: Sabate' E, editor. Adherence to Long-Term Therapies: Evidence for Action. Geneva (Switzerland): World Health Organization; 2003:47-58.

33. Bender B, Milgrom H, Rand C. Nonadherence in asthmatic patients: is there a solution to the problem? Ann Allergy Asthma Immunol. 1997;79(3):177-186. doi:10.1016/S1081-1206(10)63001-3

34. Milgrom H, Bender B, Ackerson L, Bowry P, Smith B, Rand C. Noncompliance and treatment failure in children with asthma. J Allergy Clin Immunol. 1996;98(6 Pt 1):1051-1057. doi:10.1016/ s0091-6749(96)80190-4

35. Horn CR, Clark TJ, Cochrane GM. Compliance with inhaled therapy and morbidity from asthma. Respir Med. 1990;84(1):67-70. doi:10.1016/s0954-6111(08)80097-2

36. Spector SL, Kinsman R, Mawhinney H, et al. Compliance of patients with asthma with an experimental aerosolized medication: implications for controlled clinical trials. J Allergy Clin Immunol. 1986;77(1 Pt 1):65-70. doi:10.1016/0091-6749(86)90325-8

37. George M. Adherence in asthma and COPD: new strategies for an old problem. Respir Care. 2018;63(6):818-831. doi:10.4187/respcare.05905

38. Normansell R, Kew KM, Stovold E. Interventions to improve adherence to inhaled steroids for asthma. Cochrane Database Syst Rev. 2017;4(4:CD012226. doi:10.1002/14651858.CD012226.pub2.

39. Randall S, Neubeck L. What's in a name? Concordance is better than adherence for promoting partnership and self-management of chronic disease. Aust J Prim Health. 2016;22(3):181-184. doi:10.1071/ PY 15140 
40. Bouwmeester C, Kraft J, Bungay KM. Optimizing inhaler use by pharmacist provided education to community-dwelling elderly. Respir Med. 2015;109(10):1363-1368. doi:10.1016/j.rmed.2015.07.013

41. Taylor YJ, Tapp H, Shade LE, Liu TL, Mowrer JL, Dulin MF. Impact of shared decision making on asthma quality of life and asthma control among children. $J$ Asthma. 2018;55(6):675-683. doi:10.1080/02770903.2017.1362423

42. Wilson SR, Strub P, Buist AS, et al. Shared treatment decision making improves adherence and outcomes in poorly controlled asthma. Am J Respir Crit Care Med. 2010;181(6):566-577. doi:10.1164/rccm.200906-0907OC

43. Foster JM, Usherwood T, Smith L, et al. Inhaler reminders improve adherence with controller treatment in primary care patients with asthma. $J$ Allergy Clin Immunol. 2014;134(6):1260-1268.e3. doi:10.1016/j.jaci.2014.05.041

44. Chan AH, Stewart AW, Harrison J, Camargo CA Jr, Black PN, Mitchell EA. The effect of an electronic monitoring device with audiovisual reminder function on adherence to inhaled corticosteroids and school attendance in children with asthma: a randomised controlled trial. Lancet Respir Med. 2015;3(3):210-219. doi:10.1016/ S2213-2600(15)00008-9
45. Morton RW, Elphick HE, Rigby AS, et al. STAAR: a randomised controlled trial of electronic adherence monitoring with reminder alarms and feedback to improve clinical outcomes for children with asthma. Thorax. 2017;72(4):347-354. doi:10.1136/thoraxjnl-2015208171

46. Otsuki M, Eakin MN, Rand CS, et al. Adherence feedback to improve asthma outcomes among inner-city children: a randomized trial. Pediatrics. 2009;124(6):1513-1521. doi:10.1542/peds.20082961

47. Bender BG, Cvietusa PJ, Goodrich GK, et al. Pragmatic trial of health care technologies to improve adherence to pediatric asthma treatment: a randomized clinical trial. JAMA Pediatr. 2015;169 (4):317-323. doi:10.1001/jamapediatrics.2014.3280

48. Halterman JS, Fagnano M, Tajon RS, et al. Effect of the school-based telemedicine enhanced asthma management (SB-TEAM) program on asthma morbidity: a randomized clinical trial. JAMA Pediatr. 2018;172(3):e174938. doi:10.1001/jamapediatrics.2017.4938

\section{Publish your work in this journal}

Patient Preference and Adherence is an international, peer-reviewed, open access journal that focuses on the growing importance of patient preference and adherence throughout the therapeutic continuum. Patient satisfaction, acceptability, quality of life, compliance, persistence and their role in developing new therapeutic modalities and compounds to optimize clinical outcomes for existing disease states are major areas of interest for the journal. This journal has been accepted for indexing on PubMed Central. The manuscript management system is completely online and includes a very quick and fair peer-review system, which is all easy to use. Visit http:// www.dovepress.com/testimonials.php to read real quotes from published authors. 